\title{
Building Bridges: African Biomedicine in Ngugi wa Thiong'o's Wizard of the Crow
}

\author{
Revathy Sivasubramaniam \\ Assistant Professor of English, Chellammal Women's College, Guindy, Chennai, Tamil \\ Nadu, India. Email: revathy.g.sivasubramaniam@gmail.com
}

\begin{abstract}
Using the insights provided by Professor Michael Worton and sociologist David Baronov, the paper strives to show that the cultural aspect of medicine is intrinsic to health and illness. This paper seeks to present the vibrancy of pluralistic medical practices in contemporary Africa through Kenyan writer Ngugi wa Thiong'o's novel Wizard of the Crow. It seeks to illustrate the pragmatic nature of African pluralistic medical practices that absorb and assimilate certain aspects from biomedicine, thereby paving the way for a distinctive blend that may rightly be termed as African biomedicine. It contends that African pluralistic medicine, biomedicine, and African biomedicine can coexist peacefully and contribute to the wellbeing of the African society in a highly globalized world.
\end{abstract}

Keywords: disease, culture, African pluralistic medicine, biomedicine, African biomedicine.

\section{Introduction}

Diseases have been afflicting humanity throughout its existence. Various communities have devised and developed strategies and methods specific to their cultural and social contexts to treat and manage diseases. The toolkit of diagnoses and treatments of each community is heavily influenced and shaped by its worldview and its culture, making culture intrinsic to the comprehension of health and disease. Professor Worton in the introduction to the book National Healths : Gender, Sexuality and Health in a Cross-Cultural Context (2004) endorses this viewpoint and notes that it is imperative to have an awareness of crosscultural and trans-historical aspects to better understand health, diseases, and their management. He calls this approach 'Cultural Medicine' (p.1). He avers that "both sickness and health are cultural as well as physical states" (p. 2) and the experience of illness is highly individual specific and culturally determined. For example, certain diseases such as leprosy, syphilis and, more recently, AIDS, have been stigmatized while tuberculosis was viewed in both negative and positive lights in $19^{\text {th }}$ century Europe. It was viewed in some quarters as a trope for sexually transmitted diseases and in others, to the contrary, as an aphrodisiac. It was also associated with the heightened imaginative faculties of Romantic poets such as Keats and Chopin. The disease had positive connotations in late $19^{\text {th }}$ century Japan as well. Thus,

The body is not a mere physical entity; it is also a cultural construct and is bound up in a complex of beliefs, assumptions, protocols, etc, of the society in which it is found. Furthermore, sickness, disease and suffering are not exclusively the domain of doctors and patients; they are also inherently - and profoundly - shared cultural phenomena. Each of us is situated in a cultural matrix, whereby the conjunction of the 'vertical' axis of history and the 'horizontal' axis of society determines much of what and how we think and behave (p.11).

It is in this context that biomedicine must be placed and its claims to universality probed and tested. Biomedicine being a universal phenomenon is a myth, rather, it is better termed ethno medicine or

(C) AesthetixMS 2020. This Open Access article is published under a Creative Commons Attribution Non-Commercial 4.o International License (http://creativecommons.org/licenses/by-nc/4.o/), which permits non-commercial re-use, distribution, and reproduction in any medium, provided the original work is properly cited. For citation use the DOI. For commercial re-use, please contact editor@rupkatha.com. 
Western medicine by virtue of it having its origins in the West. It is imperative to view biomedicine in its entirety, rather than solely as a scientific conception.

\section{Biomedicine: A Holistic Perspective}

Biomedicine came into being in the mid-19 ${ }^{\text {th }}$ century and established itself as a touchstone for the comparison and testing of the efficacy of other medical systems. In his book The African Transformation of Western Medicine and the Dynamics of Global Cultural Exchange (2008) sociologist David Baronov asserts that biomedicine is a "historical-cultural formation across the capitalist world system" (p.34) and it is necessary to take the dialectical relationship of biomedicine as a "scientific enterprise, as a symboliccultural expression and as an expression of social power" (p.34) into account.

The idea of biomedicine as a scientific enterprise took roots in $18^{\text {th }}$ and $19^{\text {th }}$ centuries with major breakthroughs in experimental pathology, technological innovations and significant contributions of the Paris School that ushered in radical thinking among practitioners. Viewing the human body as a machine, and a diseased body as a malfunctioning unit that requires repair, it placed emphasis on empiricism, objectivity, standardization, and clinical testing, among others. Based on a positivist approach it firmly established itself in the public imagination. But this is just a partial view.

Biomedicine as a symbolic-cultural expression shows that it is neither ahistorical nor acultural and underscores that it has been significantly shaped by the worldview of Western capitalist society. The development of biomedicine needs to be contextualized within the ideological and social transformations brought out by thinkers like Locke, Newton, Bacon and the Age of Reason. There was a major shift in thinking from belief in God's will to the ability to control nature for one's own progress. These sociocultural influences shaped biomedicine and laid the path for empirical thinking. It led biomedical practitioners to seek causes for diseases in the natural world and anything beyond it was deemed superstitious and primitive. The positivist approach of biomedicine is the culmination of thoughts, ideologies and developments that took place in the West in $18^{\text {th }}$ and $19^{\text {th }}$ centuries.

Biomedicine as an expression of social power reminds us that it rose in capitalist Western Europe and North America during the $19^{\text {th }}$ century. Private corporate interests were instrumental in its growth. Healthy workers are a prerequisite for generating profits and corporate investment in biomedicine held a steady promise of eradicating diseases and increasing productivity. To that end, heavy funds were pumped in for the setting up of medical institutions, streamlining and regulating of medical courses and licensing systems, thereby enforcing standardization.

Colonialism was a catalyst that aided the global spread of biomedicine and its hegemonic grip over the world. Tropical medicine, an offshoot of biomedicine specializing in the treatment of tropical diseases that the Western colonizers had not been exposed to earlier, was a direct consequence of colonialism. By offering cure for tropical diseases to the Westerners, it aided the perpetuation of European rule over Africa. Many of these diseases had not been a concern for the Africans themselves till the advent of colonialism since their way of life emphasized harmony with nature. The change in the living conditions of Africans due to colonial policies made them vulnerable to tropical diseases as well. They too had to take recourse to tropical medicine for quick cure, much to the detriment of their own, pluralistic system of medicine.

Before proceeding further, it is necessary to unpack African pluralistic medicine. It is not a monolith; rather, it is an eclectic, heterogeneous set of medical practices that is dynamic in nature. There, however, are certain common features among them which include

Holistic frameworks, pragmatic attitudes toward alternative medical systems (including biomedicine), the role of empirical- rational methods of investigation, and the hybrid nature of health-related services as both a profitable commodity and a social obligation (Baronov, 2008, p.128). 


\section{Bridging the Gap: African Biomedicine}

Through numerous cross-cultural encounters due to migration, trade, war, and conquest, African pluralistic medicine constantly adopted and adapted to various influences. It was no different in its encounter with biomedicine with the outcome being African biomedicine, an alternative, distinctive medical system that liberally draws from both African healing systems and western biomedicine. For instance, practitioners of African biomedicine have adopted the use of syringe in their healing system. Unlike biomedicine's sole reliance on the physical world for the comprehension of diseases, African biomedicine does not distinguish between the natural, supernatural and the social worlds. It views them as being interrelated and adopts a holistic approach. It also relies on empirical-rational methods and attributes various illnesses to infections and numerous other environmental factors and accordingly sets out to treat them. In fact, the Western pharmaceutical industry has learned and benefited from African botanical drugs - products of extensive trial and error experimentation. Most importantly, African biomedicine uses biomedicine to supplement rather than to supplant its medical system.

\section{African Biomedicine in Wizard of the Crow}

Set in contemporary times, Ngugi wa Thiong'o's Wizard of the Crow revolves around a project called 'Marching to Heaven' (p.16) proposed by the unnamed dictatorial Ruler's sycophant ministers to build the world's tallest building as a birthday gift to him. It reveals the corruption and ineptitude that has seeped the ruling elite in that country and exposes the powerful, global forces of the capitalist West that rule the country through them. The citizens of the country unite to resist the despot, throwing up various possibilities for collaboration and hybridization in a globalized world. The novel uses satire, magic realism, orature techniques and parody to depict the ills that plague several countries in the African continent due to ineffectual rule by dictators.

The novel begins with a mystery surrounding the strange illness of the Ruler, the unnamed dictator of a fictitious country named 'Free Republic of Aburiria' (Thiong'o, 2007, p.3). Several rumours abound regarding the Ruler's illness. The Ruler's illness can be viewed as a heuristic device used by Thiong'o' to expound his ideas on the relevance of African pluralistic medical practices in contemporary times, and on African biomedicine bridging the gap between biomedicine and African medical practices.

Upon the Global Bank's refusal to fund the Marching to Heaven project, the Ruler's body bloats, and he loses his sense of speech. When the Ruler's illness cannot be cured by western medicine, Kamiti, the diviner from Aburiria is summoned to America where the Ruler is stationed. Kamiti, a descendant of a lineage of seers is well educated and spiritually inclined. Gifted with the power to depart from his physical body and fly as a spirit and with a strong sense of smell that enables him to spot corruption and evil, he thinks of "the prophets of old, Confucius, Gautama Buddha, Moses, John the Baptist, Mugo wa Kibiru, who had all retreated into the wilderness to commune, in total silence, with the law that held the universe together" (Thiong'o, 2007, p.47) during his flights. He is often preoccupied with existentialist questions such as "who created the universe? The lives in the bodies that die - where do they go? Or is life an illusion? Maya, as the Indian Shankara would teach" (Thiong'o,2007, p.88).

Kamiti is very professional and scientific in the way he treats his patients, and, in the case of the Ruler, he genuinely seeks to understand the treatment administered by the Western physicians. He thus comes across as a refined, mature individual who seeks out the positive aspects of other cultures and strives for a hybridized, improved outcome in his interactions with them. For him, knowledge is a universal fountain from which he is fortunate enough to draw. It is important to note that he does not seek to propagate his beliefs or impose them on the people around him. On the other hand, Dr. Furyk, the western physician, is dismissive and condescending of Kamiti's methods and calls him a witch doctor which betrays his scientific orthodoxy. The method of divination Kamiti uses to cure the Ruler is similar to modern day psychological counselling where the psychologist asks a series of questions to the patient to get the troubling thought out of the patient from his own mouth. In the case of the Ruler, it is the slight he suffers at the hands of the Global Bank that refuses him funds for the Marching to Heaven project that causes his 
body to hypertrophy. By helping the Ruler relieve his repressed thoughts, Kamiti manages to restore the Ruler's sense of speech and control the swelling of the body.

Instead of appreciating Kamiti's skills, Dr. Furyk loses his cool and does not wish to give Kamiti any credit. He sees the whole affair as "Science versus sorcery. The battle between me and the Wizard of the Crow was shaping up as one between darkness and light; I felt connected to a long line of Christian soldiers all the way back to the Holy Crusades" (Thiong'o, 2007,p. 493); strong evidence of the cultural aspect being intrinsic to medicine and the treatment of diseases. The cultural bias of Dr. Furyk is exposed when he immediately likens Kamiti's treatment to sorcery and darkness. It reflects his condescension towards alternative medical systems. Speaking of the role of medicine in perpetuating the hegemony of the West, Fadlon (2005), medical anthropologist says:

Despite postmodern declarations regarding the presumed death of grand (and hence hegemonic) narratives, one such "grand narrative" is alive and well in medicine. This global discourse of Western medicine is commonly referred to as "biomedical culture" by sociologists and has provided an instance of expansion of ideas and practices from the center to the periphery (p.2-3)

Thus, in spite of all their pretensions of superiority for being civilized and being men of science and logic, the Western doctors come across as narrow-minded and straight-jacketed in their thinking, while Kamiti is willing to examine and imbibe whatever they have to offer in terms of knowledge from them. It reflects the pragmatic nature of African pluralistic medicine.

Through his divination, Kamiti also cures Tajirika, a rich businessman who suffers from 'whiteache' (Thiong'o, 2007, p.180). When Tajirika is made the chairman of the Marching to Heaven building Committee, he receives a lot of money as bribe from several businessmen in the hope that they would be awarded tenders in the near future. The sudden increase in money makes him want to get rid of his black skin and become white, so as to distinguish him from other rich blacks whom he is confident of leaving far behind. Soon after this he is unable to talk and the only word that comes from his mouth is if and whenever he sees a mirror, he scratches his skin indefinitely. Tajirika's wife Vinjinia brings her husband to meet Kamiti. Through his questioning and patient listening, Kamiti helps Tajirika go back in time to get to the root of his problem and, finally, towards the end of the session, helps him overcome his 'white-ache'.

Initially sceptical of Kamiti's ability to cure their afflictions and viewing his methods solely through the lens of Christianity, a couple named Maritha and Mariko brand Kamiti's divining abilities as 'satanic rites' (Thiong'o, 2007,p. 276) and visit his shrine to convert him to Christianity. This is another indication of the intertwined nature of medicine and culture, of which religion is an inseparable part. It also illustrates the condescension of Christianity towards native religions. The couple, however, change their opinion about Kamiti after he cures them of their temptation to indulge in infidelity by very rationally impressing upon them that they needed to reinvent their own sex lives to infuse life into their marriage. The Christian priest whose help they initially seek, in contrast, vaguely talks in terms of God and Satan and fails to cure them.

In addition to healing through divination, Kamiti is knowledgeable in 'herbology' (Thiong'o, 2007, 57) which he uses to cure people of their physical and mental maladies. He supplements whatever knowledge he already has about herbs with a course he does on herbs in India. Stating that respect for nature and humility are at the core of traditional medicine he says:

Nature is the source of all cures. But we have to be humble and willing to learn from it. I supplemented what I already knew with what I gleaned from my contact with Indian healers of the Western Ghat hills, places like Kottakal, Ernakulam- siddhar healers especially. (Thiong'o, 2007, p.267)

Kamiti establishes his reputation as a healer and as a wizard and people suffering from various illnesses come to consult him. Along with his partner Nyawira, he sets up 'The House of Modern Witchcraft and Sorcery' (Thiong'o, 2007, p. 274) in the outskirts of a town called Santalucia. They charge a nominal fee for the treatment they offer, but they never turn away any patient who cannot afford to pay them fees. While Kamiti primarily relies upon divination to treat his patients, he emphasizes on the importance of 
leading a healthy life. He distributes copies of the 'Seven Herbs of Grace' (Thiong'o, 2007, p. 275) to his patients in which he jots down the principles of healthy living.

Take care of the body, for it is the temple of the soul

Watch ye what you eat and drink all the time

Greed makes death greedy for life

Cigarettes arrest life; alcohol holds the mind prisoner

Life is a common stream from which plant, animal, and humans draw

The good comes from balance

Don't abandon yours for a mirage (Thiong', 2007, p. 275).

Thus, his emphasis is more on leading a healthy life and his approach to medicine, holistic, with focus more on healing and prevention of disease rather than on curing. Akin to any African pluralistic medicine, his mode of treatment does not draw any distinction between body and mind. To drive home the point of adopting a healthy lifestyle among people, he even allots a day every month called 'the Day of the Way' (Thiong'o, 2007, p.276) on which he talks about the benefits of healthy living, stressing the need to adopt the 'Seven Herbs of Grace' as part of their life. Keeping their nourishment needs in mind, the destitute among his patients are also offered food for free.

When Kamiti is shot and injured in a melee that ensues after a gathering of the people is disrupted by the Ruler's men, he is rescued by Nyawira and taken to the hospital run by the 'Movement for the Voice of the People'. His life is saved by treatment that is a combination of traditional and modern medicine -an instance of synergies between different cultural systems.

Upon recovery, Nyawira takes him to the premises the movement functions out of, to meet the central committee to have him absorbed as a member. He is taken to a hospital where Nyawira tells Kamiti that she wants him to take charge and develop the hospital into a 'nursery of health' (Thiong'o, 2007,p. 759) using his knowledge of herbology, clearly demonstrating the open-mindedness and symbiosis that is required between biomedicine and traditional systems of medicine.

\section{Conclusion}

The novel, thus, shows how two systems, rooted in fundamentally different philosophies, can still establish a mutually beneficial dialogue between themselves. The barriers to arriving at a hybridized middle ground are not as much in the methods and the tools adopted as they are in mindsets and attitudes. The hegemony of biomedicine would deprive the world of the centuries of wisdom accumulated by several cultures around the world through trial and error. At the same time however, an obstinate refusal by traditional systems of medicine to not partake of the learnings of biomedicine would result in inward-looking, closed systems that would rapidly atrophy. This is aptly summed up by social anthropologist Munyaradzi Mawere, (2014) who says "There should be no quarrel between science and indigenous knowledge: the two should be understood as complements that both work towards problem solving and where necessary can work together to enhance each other" (p.123). Today's globalized world permits communication at speeds inconceivable till even a few decades ago. This throws up several opportunities for the two systems to complement each other. While biomedicine has its forte in curing, in a protocol based, universal form of treatment, traditional systems derive their edge from local knowledge from both a natural medicine and cultural point of view. These systems, therefore, excel in prevention of disease and healing. In general, mankind would benefit immensely from seeking mutually enriching outcomes from the many, and exponentially increasing, interactions, in almost every sphere of human endeavour. 


\section{References}

Baronov, D. (2008). The African transformation of western medicine and the dynamics of global cultural exchange. Retrieved from https://ebookcentral-proquest-com.library.britishcouncil.org.in:4443

Fadlon, J. (2005). Negotiating the holistic turn : The domestication of alternative. Retrieved from https://ebookcentral-proquest-com.library.britishcouncil.org.in:4443

Mawere, M. (2014). Culture, indigenous knowledge and development in africa : Reviving interconnections for sustainable development. Retrieved from https://ebookcentral-proquestcom.library.britishcouncil.org.in:4443

Thiong'o', N. wa. (2007). Wizard of the Crow. New York: Anchor.

Worton, M. (2004). Introduction. In Worton, M., \& Wilson, T. W(Eds), National healths : Gender, sexuality and health in a cross-cultural context (p.1-20) Retrieved from https://ebookcentral-proquestcom.library.britishcouncil.org.in:4443

Revathy, M. G.(2016). "Celebrating Plurality: Cultural Globalization in the Select Works of Ngugi wa Thiong'o”.[Unpublished Doctoral Dissertation]. University of Madras. 